\title{
Features of Currents on the Black Sea Northwestern Shelf Based on the Numerical Simulation Results
}

\author{
V. L. Dorofeyev, L. I. Sukhikh ${ }^{凶}$ \\ Marine Hydrophysical Institute of RAS, Sevastopol, Russian Federation \\ \.sukhikh@gmail.com
}

\begin{abstract}
Purpose. The work is aimed at studying the features of currents on the Black Sea northwestern shelf based of the reanalysis results, and at analyzing the reasons of these features.

Methods and Results. To analyze the currents on the northwestern shelf, applied were the results of physical reanalysis of the Black Sea fields performed by the authors earlier, namely, the arrays of hydrodynamic fields on a regular grid with the 21-year duration (1992-2012). Surface currents on the northwestern shelf of the Black Sea are directed mainly to the southwest. Throughout the whole year (except for the summer months when the wind effect weakens), an intensive compensatory current directed to the south is formed along the western coast. The waters near the western coast are highly horizontally stratified that is caused by fresh water inflowing with the river runoffs. In winter seasons, the stratification is most pronounced, whereas in summer, the horizontal density gradient decreases. The horizontal density stratification leads to the following: starting from the depth $\sim 20 \mathrm{~m}$, the pressure gradient changes its sign and the along-coastal jet countercurrent directed to the north, occurs.

Conclusions. The performed studies have shown that the water circulation on the Black Sea northwestern shelf is determined mainly by the following factors: the wind-induced water flows across the shelf boundary and strong horizontal water stratification near the western coast resulted from the river runoffs. As the currents on the sea surface are directed mainly to the southwest, the compensatory current directed to the south is formed near the western coast. Due to the strong horizontal stratification resulted from the river runoffs, a countercurrent directed to the north is formed in the subsurface layer near the western coast. In case the seawater flows to the shelf are extremely high, the countercurrent may be absent.
\end{abstract}

Keywords: Black Sea, circulation, reanalysis, northwestern shelf, countercurrent

Acknowledgements: the work was carried out at support of project No. 0827-2021-0002.

For citation: Dorofeyev, V.L. and Sukhikh, L.I., 2021. Features of Currents on the Black Sea Northwestern Shelf Based on the Numerical Simulation Results. Physical Oceanography, [e-journal] 28(4), pp. 426-437. doi:10.22449/1573-160X-2021-4-426-437

DOI: 10.22449/1573-160X-2021-4-426-437

(C) V. L. Dorofeyev, L. I. Sukhikh, 2021

(C) Physical Oceanography, 2021

\section{Introduction}

The Northwestern Shelf (NWS) is the largest shallow part of the Black Sea. It covers $16 \%$ of the total area of the basin. At the same time, most of the fresh water entering the Black Sea with river runoff (approximately 65\%) falls on the NWS, where the largest rivers in Europe, such as the Danube, the Dnieper and the Dniester, inflow. The importance of this region for the formation of the Black Sea waters thermohaline and biogeochemical structure is determined mainly by the large amount of nutrients that are carried out with river runoffs (together with fresh water) and are distributed by currents throughout the Black Sea. The anthropogenic load from rivers flowing into the Black Sea northwestern region affects the state of the entire marine ecosystem. Due to the significant fresh water influx and the shallow depth, the water circulation in the NWS has its own 
characteristics in comparison with the deep-water part of the basin. Surface currents in the NWS area have been studied in many works both from field measurements and using mathematical modeling. With the help of numerical modeling within the framework of a homogeneous sea model, The wind-induced circulation in the NWS was considered, in particular, within the uniform sea model using the numerical modeling [1]. In later works, with the help of complete models, the schemes of currents at the NWS were studied, taking into account such an important factor as river runoff (for example, in [2, 3]). So, in [2], subsurface counter-currents were found as elements of water circulation in the NWS. This paper studies the structure of currents in the NWS based on the results of the previously performed retrospective analysis (reanalysis) of the Black Sea hydrodynamic fields [4], analyzes the role of wind action and river runoff the main factors that form the circulation structure.

\section{Materials and research methods}

In the presented work, we used the reanalysis results obtained from numerical integration of the equations of the Black Sea circulation model with the assimilation of satellite measurement data. One of the versions of the Black Sea circulation model created at MHI was used as a circulation model [5]. The model is based on a system of primitive equations, has $4.8 \mathrm{~km}$ spatial step, which provides adequate description of both large-scale and synoptic processes. The model contains 35 design levels, condensing towards the sea surface. Vertical turbulent diffusion and viscosity are parameterized using the depth and time dependent coefficients. In addition, an optical model for calculating the penetrating short-wave radiation [6] is included. In the sites of inflow of rivers and straits, the monthly average climatic discharge values were set.

Atmospheric fields obtained from ERA-Interim (ECMWF) reanalysis data [7] were used as boundary conditions for the circulation model equations on the free sea surface: wind stress (every 6 hours), heat and fresh water fluxes, and solar radiation (every 12 hours). The spatial resolution of these fields was originally $0.75^{\circ}$. For further use when integrating the equations of the circulation model, they were interpolated to the model grid.

When carrying out the reanalysis, measurement data assimilation is important. In this work, the sea surface temperature (SST) data, elevation anomalies, and average annual temperature and salinity profiles were used for assimilation. SST for 1993-2009 were taken from GHRSST and NODC archives, and for 20102012 - from OSI TAC archive. In order to assimilate the sea level anomaly data, we used all the available satellite altimetry data for the reanalysis period provided by the archives of NASA, AVISO, and SL TAC. The average annual temperature and salinity profiles were prepared by V.N. Belokopytov based on all hydrographic surveys available for the period under consideration and data from floating buoys.

The reanalysis results are three-dimensional hydrodynamic fields on a regular grid, covering a period of 21 years. Since the main attention in the work is paid to the general regularities of circulation in the NWS, we mainly considered the monthly average fields, which were used to obtain the monthly average climatic (i.e. averaged over 21 years) fields. 


\section{Results}

The water circulation in the Black Sea surface layer is well studied. Basically, it has a cyclonic character (for example, [1]), which is due to the predominance of positive values of the vertical component of the wind stress vorticity field over the region. The most pronounced feature of circulation in the upper sea layer is the Rim Current (RC), which forms a large-scale cyclonic gyre. In the summer season, the intensity of wind impact weakens and, as a result, the energy of surface currents decreases. At this time, the circulation pattern becomes less ordered, breaking up into a series of eddies. This circulation scheme is, of course, simplified.

The Rim Current behavior near the eastern edge of the shelf, where it changes direction, is decisive for the formation of currents in the NWS. Sometimes an intense Rim Current jet enters partly on the shelf, and sometimes moves away from its edge. In the first case, a powerful flow of water is formed from the deepwater part of the sea to the NWS, which significantly affects the circulation of waters in the shelf zone. Based on the results of reanalysis [8], it was demonstrated that the water flow in the sea surface layer through the shelf edge, passing along the $200 \mathrm{~m}$ isobath, is mainly directed from the deep-water part of the basin to the shelf. The direction of the water flow through the shelf edge (together with the wind effect) is one of the key factors determining the circulation at the NWS in the surface layer. At the same time, the presence of a large amount of freshened water near the western coast, due to the river runoff (mainly the Danube), significantly affects the formation of the pattern of currents in the sea subsurface layer.
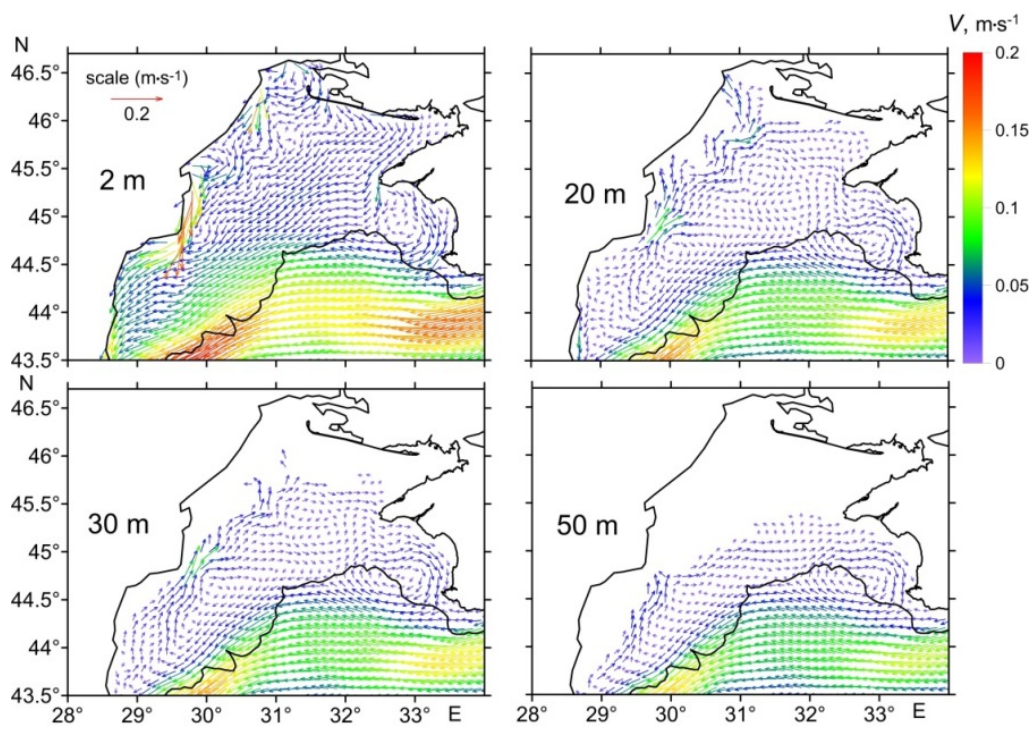

F i g. 1. Maps of the currents (average over the whole period) on the NWS at different horizons

Now we are to consider the average water circulation in the NWS in the sea surface layer at different horizons, obtained by averaging over 21 years (Fig. 1). 
On the sea surface, in most of the NWS, the currents are directed to the southwest, which is due to the Rim Current effect, the jet of which partially enters the shelf, and the wind effect. The water flow is pressed against the western coast, which causes an intensive compensatory alongshore current directed to the south. In addition to the Rim Current and alongshore current, the manifestation of Sevastopol anticyclone is clearly visible. In the subsurface layer the picture changes. At the horizons below $20 \mathrm{~m}$, the Rim Current jet and Sevastopol anticyclone appear distinctly, but the alongshore current reverses direction. Moreover, this countercurrent is observed up to $50 \mathrm{~m}$ horizon.

Seasonal cycle of changes in the surface circulation at the NWS is shown in Fig. 2 in the form of current maps for six months. In winter (December and February), the Rim Current jet is intense and partially enters the shelf. The Sevastopol anticyclone is pressed against the western Crimean coast. In the main part of the shelf, the surface current is directed to the southwest. An intense alongshore current directed to the south is clearly visible along the western coast of the sea. In April and June the Rim Current jet moves away from the shelf edge eastwards of $31^{\circ} \mathrm{E}$. Sevastopol anticyclone is not identified on the April map of currents, but on the June map it is located far from the Crimean coast. The alongshore jet current in April is noticeable only in the southern part, and in June it is absent. In August and October the Rim Current is blurred and its intensity decreases.
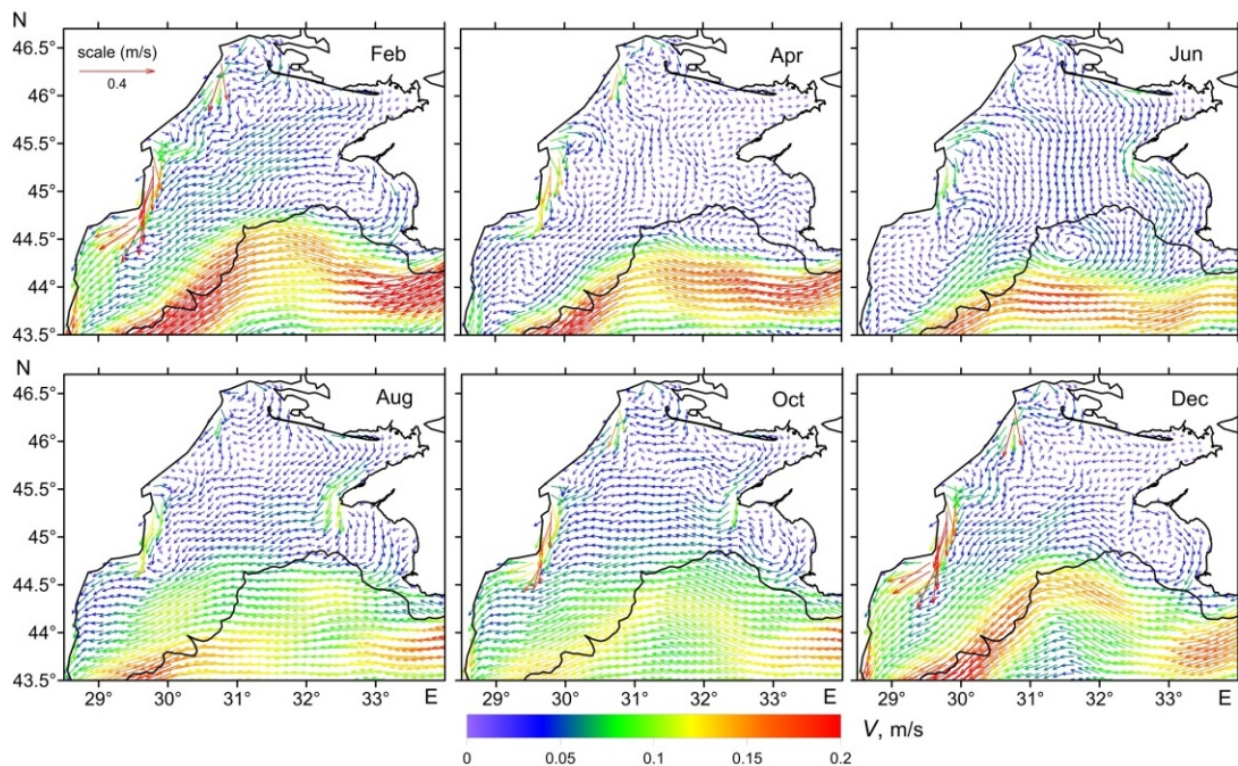

F i g. 2. Maps of the monthly average climatic surface currents on the NWS

Thus, in the months when the Rim Current jet enters the NWS, and this is observed mainly in the winter season, an intense alongshore current directed to the south is clearly visible, which compensates for the water inflow from the Black Sea deep-water part to the shelf. In those months when the Rim Current moves away from the shelf edge or its intensity is not high, the alongshore current is either PHYSICAL OCEANOGRAPHY VOL. 28 ISS. 4 (2021) 
weak or absent. It is shown in [7] that the water flow in the upper layer of the sea through the NWS edge, limited by the $200 \mathrm{~m}$ isobath, is determined by the location of the Rim Current jet, which, in its turn, depends on the vorticity of the wind stress field over the Black Sea western part. In Fig. 3 the monthly average climatic values of the corresponding values are presented.

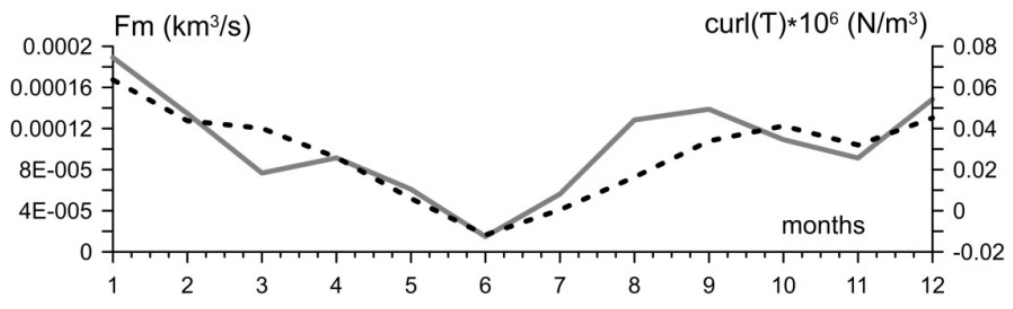

F i g. 3. Monthly average climatic values of water mass fluxes on the NWS through the section along the $200 \mathrm{~m}$ isobath (solid line) and vorticity of the wind stress field over the western part of the Black Sea (dashed line)

There is a good correlation between the values of the fluid mass flow and the wind field vorticity. The higher the vorticity value, the greater is the water flow through the lateral section of the shelf, and, accordingly, the more intense the alongshore compensation current to the south. In June, the vorticity of the friction stress field is minimal; accordingly, the water flow to the shelf is also minimal, and, as can be seen in Fig. 2, the alongshore current directed to the south is absent on the climatic map.

The presence of a large amount of freshened water caused by river runoff is a characteristic feature of the Black Sea NWS. In Fig. 4 the monthly average climatic maps of the surface water density distribution obtained from the reanalysis results are given. The influx of large quantities of fresh water causes strong horizontal density stratification. The most pronounced horizontal stratification is manifested in winter, when surface currents caused by wind effect press the desalinated waters to the west coast. In summer, the area of desalinated water increases, while the horizontal density gradient decreases.

In addition to the circulation, this is also due to the fact that in June the river runoff reaches its maximum. As can be seen in Fig. 4, the general level of density in summer is significantly lower, which is caused by the temperature effect on the seawater density. The vertical distribution of water density near the coast is shown in Fig. 5 in the form of sections along $45^{\circ} \mathrm{N}$. The density is highly stratified horizontally. This is especially evident in February. This month the density of seawater is almost uniform in the vertical direction due to intense mixing caused by strong winds and thermal convection. In summer, the horizontal density gradient decreases, but a noticeable vertical stratification appears. Such features of the density distribution in the NWS coastal zone lead to the fact that currents at the depth significantly differ from currents in the sea surface layer. 

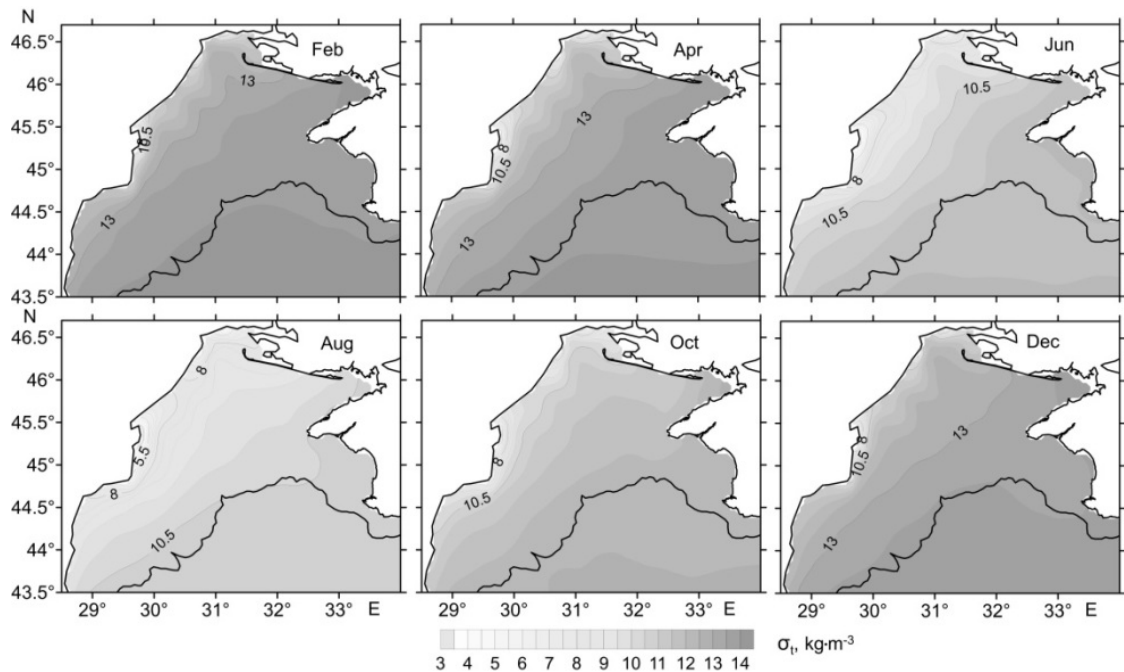

F i g. 4. Maps of distribution of the monthly average climatic surface density $\sigma_{t}=\left(\rho-\rho_{0}\right), \rho_{0}=1000 \mathrm{~kg} / \mathrm{m}^{3}$
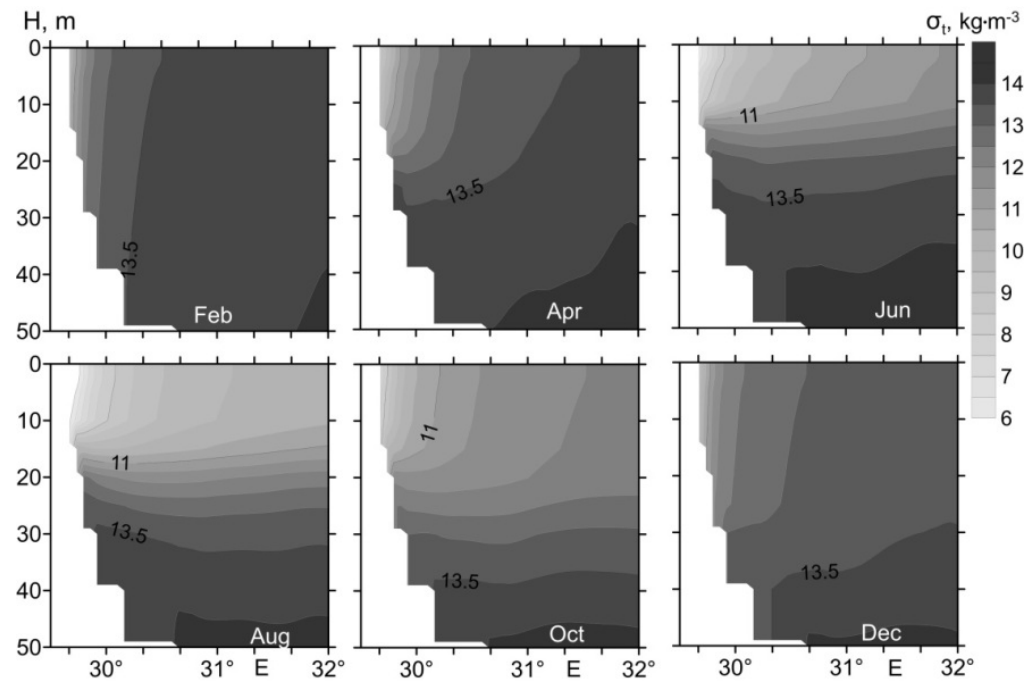

F i g. 5. Zonal sections of the monthly average climatic density $\sigma_{t}$ along $45^{\circ} \mathrm{N}$

In Fig. 6 the maps of currents at $20 \mathrm{~m}$ depth on the NWS for the same months as in Fig. 2 are given. In the area of the shelf sea boundary on all the presented maps at $20 \mathrm{~m}$ depth, as well as in the surface layer of the sea, the currents directed to the southwest are observed, which is a manifestation of the Rim Current. All the maps also show the Sevastopol anticyclone. An essential distinctive feature of the current pattern at $20 \mathrm{~m}$ depth is the alongshore current directed to the north, opposite to the direction of the alongshore current in the surface layer. Moreover, this current at $20 \mathrm{~m}$ depth is observed in all months. The presence of an alongshore current directed to the north is the result of horizontal density stratification of waters caused by the influx of a large volume of fresh water into the surface layer 
with river runoff. The pressure deviation from the mean value at the horizon is determined by the formula

$$
P=\rho_{s} g \zeta+g \int_{0}^{z}\left(\rho\left(x, y, z^{\prime}\right)-\rho^{*}\left(z^{\prime}\right)\right) d z^{\prime},
$$

where $\rho_{s}$ is a water density at the sea surface; $\zeta$ is a free surface elevation; $\rho^{*}(z)$ is a mean density at a horizon; $\rho(x, y, z)$ is a seawater density; $\mathrm{g}$ is a gravitational acceleration.

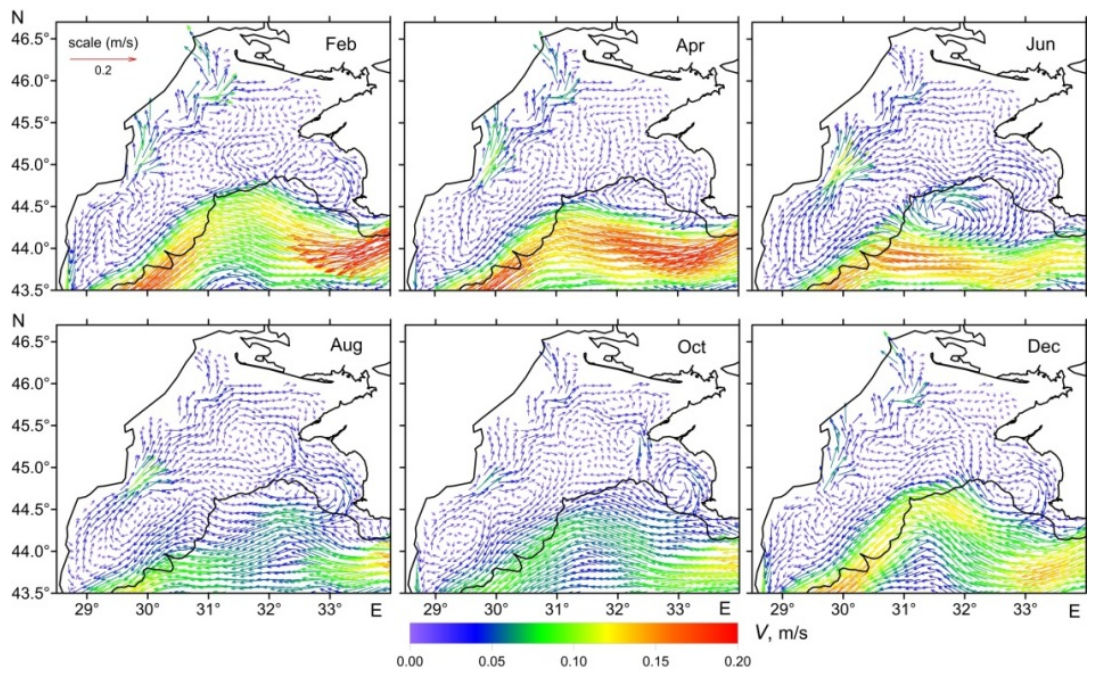

F i g. 6. Maps of the monthly average climatic currents on the horizon $20 \mathrm{~m}$
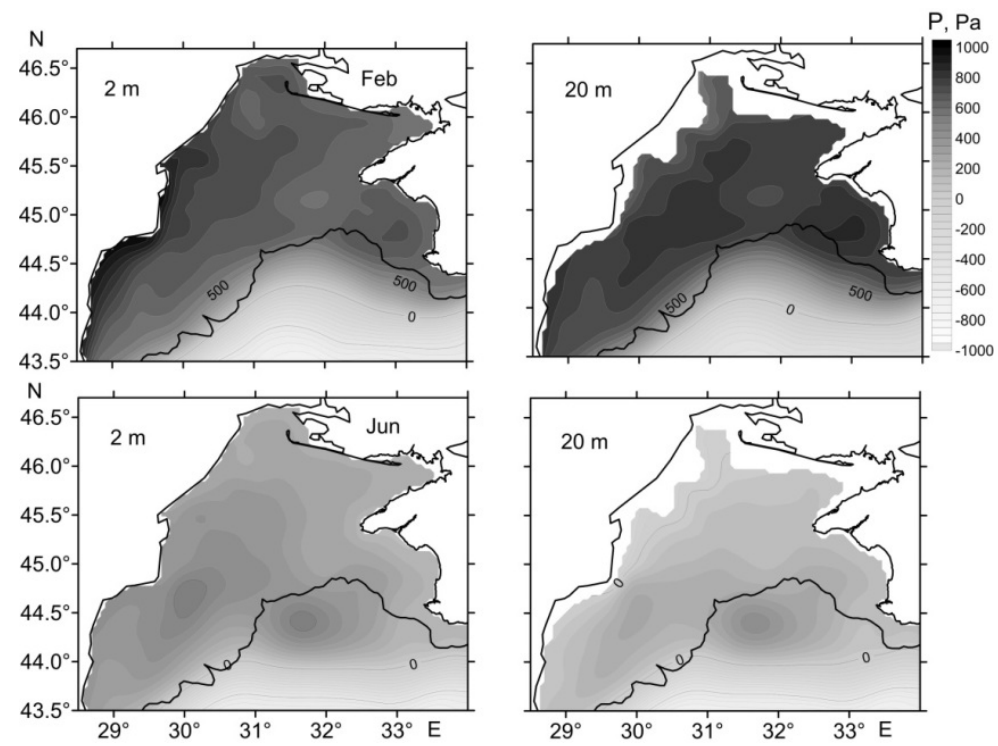

F i g. 7. Distribution of the monthly average climatic values of pressure on the upper horizon and at the $20 \mathrm{~m}$ depth for February (above) and June (below). The deviation from the mean on the corresponding horizon is shown $(\mathrm{Pa})$ 
The pressure is thus determined by two terms. The first is the contribution of free surface elevation, the second is the contribution of the integral water density at a given horizon. On the sea surface only the first term works. Therefore, when the surface currents are directed towards the western coast (see Fig. 1, 2), the level of the free surface near it rises. As a result, the pressure becomes higher near the coast and a southward current is formed. With an increase in the depth of the horizon under consideration, the pressure value begins to be affected by the second term, which depends on the water density. Due to the strong horizontal stratification caused by freshwater near the coast, the second term in expression (1) works in such a way that the gradient of this part of the pressure is directed away from the coast. At some depth, the contribution of the second term may become dominant, and the pressure near the coast will be lower. In this case, the alongshore current will be directed to the north. That is, there is a classic countercurrent, when on the surface water flows in one direction, and at a certain depth - in the opposite one. This situation can be seen in Fig. 1 and 6. In order to illustrate the facts described above, Fig. 7 represents the pressure distributions on the upper horizon (in this case, it is determined by the free surface elevation) and on $20 \mathrm{~m}$ horizon for two months: February and June. In February, an intense alongshore current directed to the south is observed on the surface, while in June such a current is absent. At $20 \mathrm{~m}$ depth, a northward current is observed in both cases. On the maps of pressure distribution in February on the surface, the pressure is higher directly near the coast, and in June the maximum pressure is shifted from the coast. At $20 \mathrm{~m}$ horizon, the maximum pressure is separated from the coastline for both months, which is explained by the effect of horizontal density stratification.

So far, we have considered the most significant features of currents in the NWS and, on the basis of the average monthly climatic fields, analyzed the causes of these features. The main factors affecting the nature of circulation in the area under consideration are wind impact and freshening of coastal waters caused by river runoff. The key factor determining the circulation of surface waters in the NWS is the flow of a liquid mass across the shelf boundary, passing along $200 \mathrm{~m}$ isobath. This flow mainly depends on how far the Rim Current jet enters the shelf. The mass flow, as shown above (Fig. 3), correlates well with the vorticity of the wind stress field. The current in the subsurface layer near the western coast is predominantly determined by horizontal density stratification. However, if we consider not the climatic fields, but the fields corresponding to a certain moment in time, then the scheme described above may change. The time evolution of the liquid mass flow in the surface layer of the sea through the NWS boundary along $200 \mathrm{~m}$ isobaths is demonstrated in Fig. 8. The flow values are calculated on the basis of the fields obtained during the reanalysis.

The graph in Fig. 8 represents monthly average values smoothed with a threemonth window width running average. According to the given graph, the water flow in the upper layer is directed mainly from the deep-water part of the sea to the shelf. Now we are to consider examples of currents at the NWS corresponding to two extreme values of the water flow. The first case corresponds to a high value of the flux to the shelf (winter 1996), and the second - from the shelf to the deepwater part of the sea (winter 2000). 


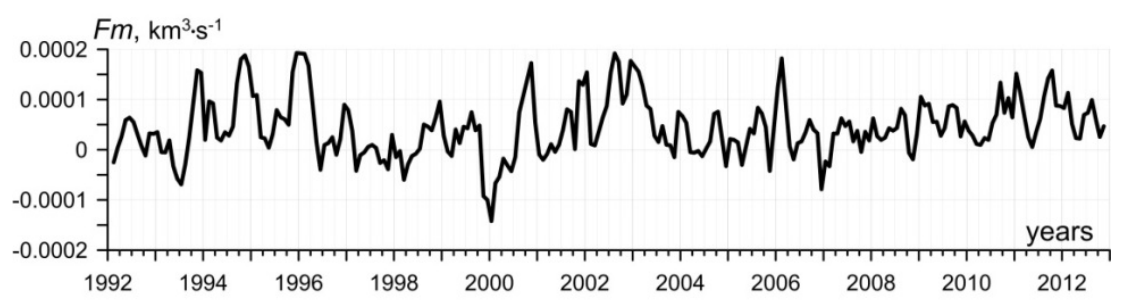

F i g. 8. Time evolution of the water mass flows on the NWS through the section along the $200 \mathrm{~m}$ isobath

In Fig. 9 the maps of the average fields for the season for the first case. The upper row corresponds to the upper horizon, the lower row - to $20 \mathrm{~m}$ horizon. On the left are maps of the currents and on the right are the maps of free surface elevation and pressure anomalies at $20 \mathrm{~m}$ depth. At the maps of currents, both on the surface and on 20 m horizon, a powerful jet of the Rim Current, which runs along the shelf boundary, can be seen. Sevastopol anticyclone is also visible on both horizons (on the surface it is not so strongly pronounced due to the wind effect on surface waters). Surface currents are directed towards the western coast. As a result, the sea level near it rises to $15 \mathrm{~cm}$, and along the coast a stream of intense compensatory current, directed to the south, is formed. At $20 \mathrm{~m}$ horizon, the currents are rather weak, but the alongshore current jet is clearly visible. Moreover, in contrast to the cases of climatic fields considered above, this current is directed to the south in the same way as the current on the surface. The pressure anomaly map shows that the pressure reaches its maximum near the coast.
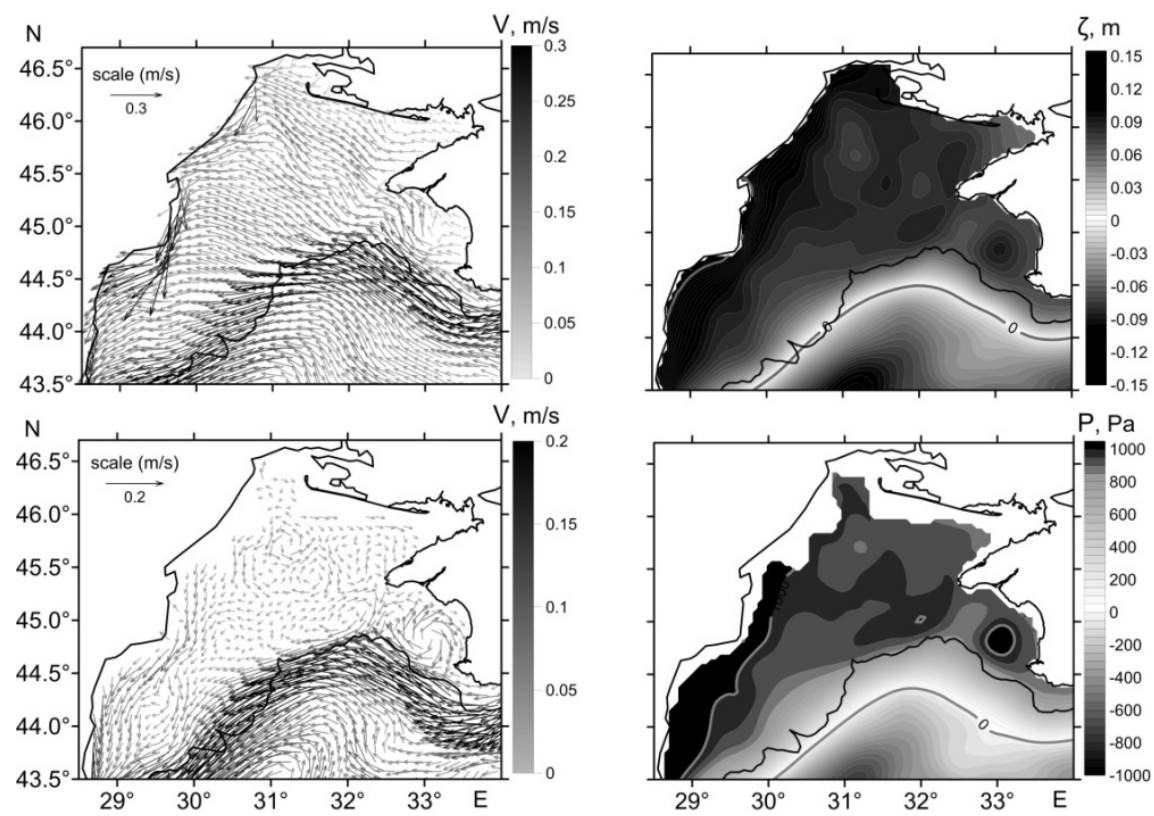

F i g. 9. Maps of the mean currents for the 1996 winter season on the surface (above, on the left) and at the $20 \mathrm{~m}$ horizon (below, on the left); distribution of the free surface elevation (m) (above, on the right) and pressure anomalies at the $20 \mathrm{~m}$ horizon (Pa) (below, on the right) 
Thus, in the case of an anomalously high value of the water flow from the Black Sea deep-water part to the NWS, the level rise near the western coast becomes so great that the effect of horizontal density stratification does not compensate in the pressure field (the second term on the right-hand side of expression (1)) the effect sea level elevation (the first term on the right side of expression (1)) with depth. As a result, both on $20 \mathrm{~m}$ horizon and on the surface, the pressure becomes higher near the coast, and the alongshore current, like the current on the surface, is directed to the south.

The fields for the winter 2000, when, according to the graph in Fig. 8, the water flow in the upper layer was directed from the shelf to the deep-water part, are presented in Fig. 10. In this case, the currents on the shelf, both on the surface and at $20 \mathrm{~m}$ horizon, are rather weak. The Rim Current jet is less intense and is located below the shelf edge. Accordingly, the level rise near the western coast is small, and the alongshore current on the upper horizon is manifested only in small areas. On $20 \mathrm{~m}$ horizon the alongshore current directed to the north is clearly visible, and the pressure maximum is located on the right of the coast. That is, in this case, the contribution of horizontal stratification in expression (1) prevails.
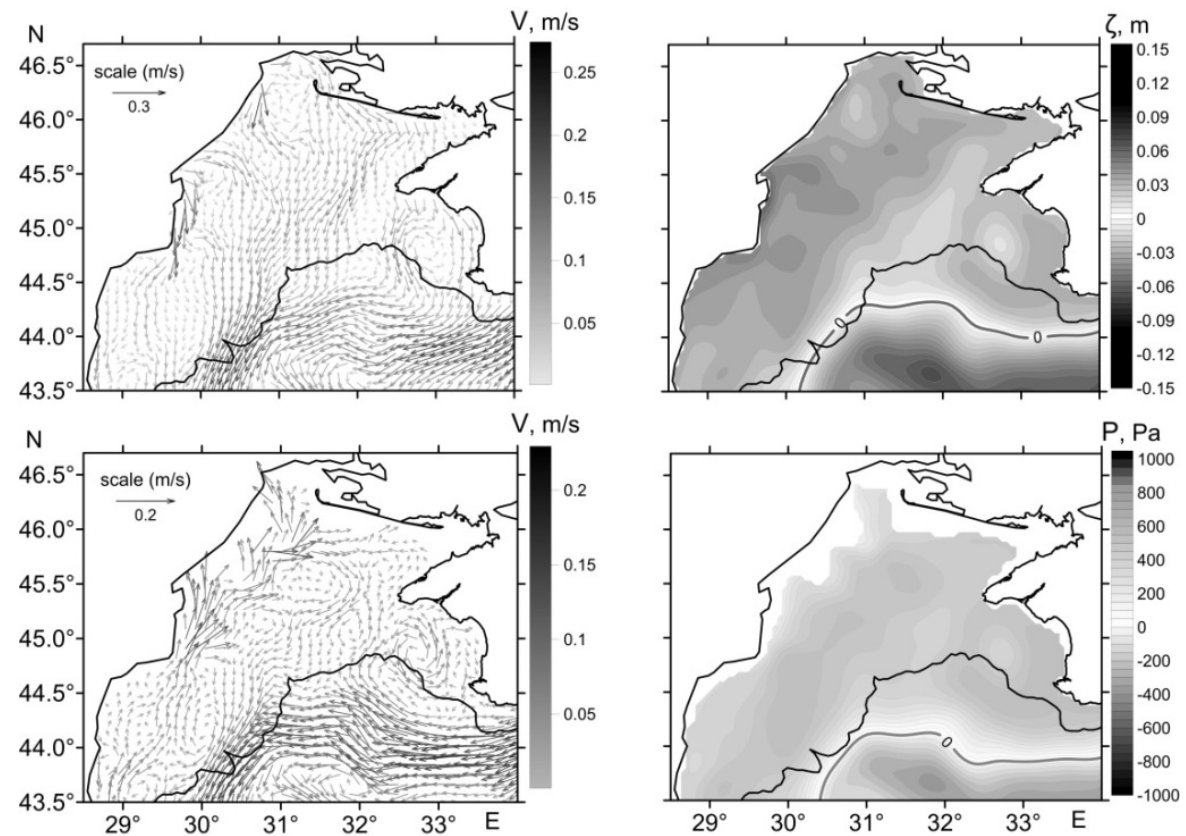

F i g. 10. Maps of the mean currents for the 2000 winter season on the surface (above, on the left) and at the $20 \mathrm{~m}$ horizon (below, on the left); and distribution of the free surface elevation (m) (above, on the right) and pressure anomalies at the $20 \mathrm{~m}$ horizon (Pa) (below, on the right)

\section{Conclusion}

On the basis of the hydrodynamic fields' array for 21 years, obtained as a result of numerical modeling with the satellite measurement data assimilation, an analysis of currents in the Black Sea NWS was carried out. Due to the wind effect, the surface currents in the NWS are directed mainly to the southwest, which PHYSICAL OCEANOGRAPHY VOL. 28 ISS. 4 (2021) 
causes an alongshore current directed to the south. The most intense currents in the surface layer are observed in winter. Accordingly, the alongshore current is most intense in this season. In summer, the intensity of currents decreases and the alongshore current may be absent. The picture of currents changes with depth. In particular, there is an alongshore countercurrent directed to the north. It should be noted that it is present on climate maps throughout the year.

It this work it is demonstrated that the alongshore current in the subsurface layer, directed to the north, is caused by horizontal density stratification, which forms as a result of fresh water inflow into the surface layer with river runoff. If the pressure on the surface is determined by the free surface elevation (as a rule, it is maximal near the coast), then with depth the factor of density field inhomogeneity, minimal near the coast, begins to affect. As a result, at 15-20 m depth, the pressure gradient changes its sign. Accordingly, the alongshore current changes its sign.

The described scheme of currents near the coast is not always observed. The sea level rise near the western boundary can reach high values at extremely high values of the water flow across the NWS boundary along $200 \mathrm{~m}$ isobath. As a result, the contribution of horizontal stratification to the pressure gradient does not compensate for the contribution from the level gradient. In this case, the alongshore current does not change its direction with depth, and the subsurface countercurrent is absent.

\section{REFERENCES}

1. Blatov, A.S., Bulgakov, N.P., Ivanov, V.A., Kosarev, A.N. and Tuljulkin, V.S., 1984. Variability of the Black Sea Hydrophysical Fields. Leningrad: Gidrometeoizdat, 240 p. (in Russian).

2. Demyshev, S.G., Ivanov, V.A., Markova, N.V. and Cherkesov, L.V., 2007. Construction of the Black Sea Currents on the Basis of Eddy Resolving Model with Assimilation of the Climatic Temperature and Salinity. In: MHI, 2007. Ekologicheskaya Bezopasnost' Pribrezhnykh i Shel'fovykh Zon i Kompleksnoe Ispol'zovanie Resursov Shel'fa [Ecological Safety of Coastal and Shelf Zones and Comprehensive Use of Shelf Resources]. Sevastopol: ECOSI-Gidrofizika. Iss. 15, pp. 215-226 (in Russian).

3. Beckers, J.M., Gregoire, M., Nihoul, J.C.J., Stanev, E., Staneva, J. and Lancelot, C., 2002. Modelling the Danube-Influenced North-Western Continental Shelf of the Black Sea. I: Hydrodynamical Processes Simulated By 3-D and Box Models. Estuarine, Coastal and Shelf Science, 54(3), pp. 453-472. doi:10.1006/ecss.2000.0658

4. Dorofeev, V.L. and Sukhikh, L.I., 2016. Analysis of Variability of the Black Sea Hydrophysical Fields in 1993-2012 Based on the Reanalysis Results. Physical Oceanography, (1), pp. 33-47. doi:10.22449/1573-160X-2016-1-33-47

5. Demyshev, S.G. and Korotaev, G.K., 1992. Numerical Energy-Balanced Model of Baroclinic Currents in the Ocean with Bottom Topography on the C-Grid. In: IVM RAN, 1992. [Numerical Models and the Results of Calibrating Currents in the Atlantic Ocean]. Moscow: IVM RAN, pp. 163-231 (in Russian).

6. Suslin, V.V. and Churilova, T.Ya., 2010. Simplified Method of Calculation of Spectral Diffuse Beam Attenuation Coefficient in the Black Sea Upper Layer on the Basis of Satellite Data. In: MHI, 2010. Ekologicheskaya Bezopasnost' Pribrezhnykh i Shel'fovykh Zon i Kompleksnoe Ispol'zovanie Resursov Shel'fa [Ecological Safety of Coastal and Shelf Zones and Comprehensive Use of Shelf Resources]. Sevastopol: ECOSI-Gidrofizika. Iss. 22, pp. 4760 (in Russian). 
7. Dee, D.P., Uppala, S.M., Simmons, A.J., Berrisford, P., Poli, P., Kobayashi, S., Andrae, U., Balmaseda, M.A. and Balsamo, G. [et al.], 2011. The Era-Interim Reanalysis: Configuration and Performance of the Data Assimilation System. Quarterly Journal of the Royal Meteorological Society, 137(656), pp. 553-597. doi:10.1002/qj.828

8. Dorofeyev, V.L. and Sukhikh, L.I., 2020. Studying the Fluxes of the Marine Ecosystem Components from the Northwestern Shelf to the Deep Part of the Black Sea. Physical Oceanography, 27(5), pp. 460-471. doi:10.22449/1573-160X-2020-5-460-471

About the authors:

Viktor L. Dorofeev, Senior Research Associate, Marine Hydrophysical Institute of RAS (2 Kapitanskaya St., Sevastopol, 299011, Russian Federation), Ph.D. (Phys.-Math.), ResearcherID: G-1050-2014, viktor.dorofeev@mhi-ras.ru

Larisa I. Sukhikh, Research Associate, Marine Hydrophysical Institute of RAS (2 Kapitanskaya St., Sevastopol, 299011, Russian Federation), ResearcherID: M-4381-2018, l.sukhikh@gmail.com

Contribution of the co-authors:

Viktor L. Dorofeev - formulation of the problem, carrying out numerical experiments, analysis of the results obtained.

Larisa I. Sukhikh - preparing data for providing the numerical computations, analysis of the results.

All the authors have read and approved the final manuscript.

The authors declare that they have no conflict of interest. 